\title{
EFEKTIFITAS PROGRAM PENGELOLAAN SAMPAH PLASTIC DI HOTEL (STUDI KASUS: PROGRAM "BYE-BYE PLASTIC 2018” DI DOUBLE TREE BY HILTON JAKARTA)
}

\author{
Regina Dewi Hanifah ${ }^{1}$, Finzky ${ }^{2}$ \\ ${ }^{1}$ D3 Perhotelan,Akademi Pariwisata Bunda Mulia, Jakarta, rhanifah@bundamulia.ac.id \\ ${ }^{2}$ D3 Perhotelan,Akademi Pariwisata Bunda Mulia, Jakarta, finzkyong@gmail.com
}

\begin{abstract}
ABSTRAK:
Berdasarkan Fauzi dan Oktavianus (2014), di Indonesia sendiri tingkat sosial dan ekonomi di Indonesia bertolak belakang dengan pembangunan lingkungan di Indonesia sendiri.Industri Perhotelan yang beroperasional 24 jam setiap harinya mulai memikirkan cara dalam pengurangan limbah dan mereka menekankan berbagai praktik baru yang dapat memotong biaya pembuangan limbah mereka, melindungi dan melestarikan alam. Double Tree by Hilton sebagai sebuah hotel bintang lima mencoba suatu langkah terbaru bernama "Bye-bye Plastic" sebagai gerakan pengurangan sampah plastik dalam hotel.

Data dalam penelitian ini bersifat kualitatif dan menggunakan pendekatan studi kasus. Teknik pengumpulan data yang digunakan adalah wawancara, observasi, studi pustaka, dan dokumen dari Hotel. Untuk mengukur tingkat efektifitas pengelolaan sampah plastik, khususnya dalam periode dimulainya Program Bye-bye Plastic 2018, Penulis menggunakan teori dari Cyprus Sustainable Tourism Initiative Theory's (2017) mengenai empat langkah pengelolaan sampah yang baik.
\end{abstract}

Kesimpulan dari penelitian ini adalah pengelolaan sampah di Double Tree by Hilton dengan program Bye-bye Plastic 2018 belum efektif dimana, dari keempat tahapan pengelolaan sampah belum semuanya dilakukan dan berhasil sempurna. Baru di dalam tahapan pertama sudah ada aksi tetapi hasil yang diberikan belum maksimal. Saran yang dapat diberikan adalah Hotel harus mengevaluasi kembali mengenai program ini, dimulai dari perencanaan program dengan detail terlebih dahulu sehingga dapat menghemat biaya dan meningkatkan kualitas lingkungan di Double Tree by Hilton Jakarta.

Kata Kunci: Pengelolaan Sampah, Sampah Plastik, Hotel

\section{ABSTRACT:}

Based on Fauzi and Oktavianus (2014), in Indonesia itself the social and economic level in Indonesia is in contrast to environmental development in Indonesia itself. The hospitality industry that operates 24 hours a day starts thinking about ways to reduce waste and they emphasize new practices that can cut their waste disposal costs, protect 


\section{National Conference of Creative Industry: \\ Sustainable Tourism Industry for Economic Development}

Universitas Bunda Mulia, Jakarta, 5-6 September 2018 e-ISSN No: 2622-7436

and conserve nature. Double Tree by Hilton as a five-star hotel tries a new step called "Bye-bye Plastic" as a movement to reduce plastic waste in hotels.

The data in this study are qualitative and use a case study approach. Data collection techniques used are interviews, observations, literature studies, and documents from the Hotel. To measure the level of effectiveness of plastic waste management, especially in the 2018 Bye-bye Plastic Program, the author uses the theory of the Cyprus Sustainable Tourism Initiative Theory (2017) regarding four good waste management steps.

The conclusion of this study is that waste management in Double Tree by Hilton with the Bye-bye Plastic 2018 program is not effective where, from all four stages of waste management, everything has not been done and it works perfectly. Only in the first stage has there been action but the results have not been maximized. The advice that can be given is that the hotel must reevaluate this program, starting from the detailed program planning in advance so that it can save costs and improve the quality of the environment in Double Tree by Hilton Jakarta.

\section{Keywords: Waste Management, Plastic Waste, Hotel}

\section{PENDAHULUAN}

Tujuan Pembangunan Keberlanjutan (Sustainable Development Goals) merupakan salah satu topik yang belakangan ini tengah menjadi sorotan utama di setiap sektor. Adapun tujuan dari pembangunan keberlanjutan sendiri menawarkan visi dunia yang lebih adil, lebih makmur, damai, dan berkelanjutan dimana tidak ada yang tertinggal. Agenda pembangunan keberlanjutan juga disepakati oleh 193 negara anggota PBB pada tanggal 2 Agustus 2015 setelah lebih dua tahun konsultasi dan bernegosiasi dimana topik ini sendiri penuh perangkap potensial. Adapun seluruh anggota PBB di dunia sepakat untuk memiliki agenda di tahun 2030 dalam mengubah dunia untuk Pembangunan Keberlanjutan. Hal ini untuk mengintegrasikan ketiga pilar yaitu ekonomi, sosial dan juga lingkungan. Dimana Tujuan Pembangunan Berkelanjutan merupakan tanggung jawab semua negara, mencakup hasil pembangunan dalam negeri, bantuan ke negara lain, dan barang publik global.Berdasarkan Fauzi dan Oktavianus (2014), di Indonesia sendiri perkembangan pembangunan berkelanjutan dapat dinilai dari Indeks Pembangunan Bekelanjutan. Dimana hasil dari penelitian tersebut ditemukan bahwa tingkat sosial dan ekonomi di Indonesia sudah meningkat tajam tetapi bertolak belakang dengan pembangunan lingkungan di Indonesia sendiri. Hal ini menjadi sebuah perhatian khusus bagi negara Indonesia untuk dapat mementingkan aspek lingkungan di semua lini yang ada. Karena pembangunan yang menitikberatkan pada salah satu dimensi saja pada akhirnya akan dikoreksi oleh degradasi dimensi yang lain.

Sebagai salah satu sektor usaha yang terus berkembang di Indonesia, sektor hotel dan resort tentunya terus berbenah untuk menjadi perusahaan terbaik bagi para pelanggannya. Adapun Tujuan Pembangunan Berkelanjutan menjadi salah satu ide yang mulai diterapkan oleh sektor perhotelan. Dimana perusahaan tidak melulu meningkatkan dimensi ekonomi dan sosialnya, tetapi juga mulai melirik dimensi lingkungan dalam tujuan perusahaan. Industri Perhotelan memulai dengan menganalisis kebutuhan pengurangan limbah dan mereka menekankan berbagai praktik baru yang 


\section{National Conference of Creative Industry: \\ Sustainable Tourism Industry for Economic Development}

Universitas Bunda Mulia, Jakarta, 5-6 September 2018 e-ISSN No: 2622-7436

dapat memotong biaya pembuangan limbah mereka, melindungi dan melestarikan alam dan juga meningkatkan loyalitas tamu. Hal ini terlihat mulai muncul banyaknya label Eco-Hotel atau Green Hotel yang menjamur di industri Perhotelan. Konsep dimana hotel mulai memperhatikan lingkungan dan kembali menggunakan bahan-bahan natural yang tidak merusak lingkungan.Salah satu jenis sampah anorganik yang susah untuk di daur ulang dan menjadi penyebab masalah lingkungan adalah sampah plastik. Menurut Kementrian Lingkungan Hidup dan Kehutanan (2016), Indonesia masuk dalam peringkat kedua di dunia sebagai penghasil sampah plastik ke laut. Hal ini dapat terlihat, sampah di Jakarta mencapai 6.000 sampai 6.500 ton per hari dan $13 \%$ dari sampah tersebut adalah sampah plastik (Geotimes, 2015).Dimana jumlah sampah untuk industri Perhotelan sendiri didukung dari jumlah tingkat hunian kamar yang dimiliki oleh setiap hotel. Karena semakin banyak tamu yang menginap maka hotel harus menyiapkan makanan dan minuman bagi mereka, begitupun untuk kebutuhan di dalam kamar yang terkadang disiapkan air minum dalam kemasan bagi para tamu.Penulis meninjau banyaknya sampah yang dihasilkan di hotel berbintang sendiri semakin banyak setiap tahunnya, dikarenakan selain hotel yang meningkat ternyata tingkat hunian kamarpun meningkat, yang berarti jumlah sampah yang dihasilkan tamu pasti bertambah banyak.

Di Indonesia sendiri masih sangat sedikit hotel yang memiliki konsep Green Hotel, dimana hotel berkomitmen ramah lingkungan. Double Tree by Hilton sebagai sebuah hotel bintang lima mencoba suatu langkah terbaru bernama "Bye-bye Plastic" dalam rangka mendukung Tujuan Pembangunan Berkelanjutan dari sisi lingkungan. Program ini merupakan progam pengurangan sampah berbahan plastik yang dimiliki oleh pihak hotel baik dari sisi tamu maupun karyawan. Hal ini menjadi sebuah perhatian khusus bagi Penulis, dimana tidak banyak Hotel yang memiliki program dalam pengelolaan sampah khususnya untuk sampah plastik. Seperti yang diketahui Hotel melakukan operasionalnya 24 jam setiap harinya dan tidak pernah berhenti dalam menghasilkan sampah ataupun limbah. Dimana pengolahan limbah yang tidak terarah dan tidak terorganisir dengan baik akan menyebabkan permasalahan di berbagai sektor seperti lingkungan dan hingga ke ekonomi dari sebuah perusahaan. Melihat tingginya tingkat sampah ataupun limbah yang dimiliki oleh pihak hotel tidak cukup bila sebuah hotel hanya menggerakkan dari sisi karyawan saja, tetapi perlu dukungan dari para tamu sebagai konsumer utamnya. Sehingga program pengelolaan sampah dapat dijaga dari titik awal sampah itu dibuat.

\section{TINJAUAN PUSTAKA}

Tujuan dari menjadi Hotel Tanpa Limbah adalah untuk membatasi sebanyak mungkin dampak negatif pada lingkungan baik dengan mengurangi konsumsi sumber daya dan dengan mengubah praktik di dalam hotel sehingga limbah yang dihasilkan dapat digunakan sebagai bahan baku. Lebih khusus lagi, pendekatan Tanpa Limbah menggambarkan perkembangan praktik dan peraturan yang mengarah pada penggunaan bahan yang efisien berdasarkan prinsip keberlanjutan dan ekonomi lingkaran. Itu berarti bahwa bahan yang sama digunakan lagi dan lagi sampai tingkat konsumsi yang optimal (Song et. al, 2014).

Menurut undang-undang nomor 18 tahun 2008, sampah adalah seluruh sisa kegiatan manusia yang dilakukan sehari-hari dan atau dari proses alam yang berciri khas 


\section{National Conference of Creative Industry: \\ Sustainable Tourism Industry for Economic Development}

Universitas Bunda Mulia, Jakarta, 5-6 September 2018 e-ISSN No: 2622-7436

padat sedangkan menurut undang-undang nomor 101 tahun 2014, limbah adalah sisa suatu usaha dan atau kegiatan.Adapun sampah digolongkan menjadi 2 golongan yaitu sampah organik dan sampah anorganik. Sampah organik adalah sisa buangan yang berasal dari makhluk hidup baik manusia, hewan maupun tumbuhan dan sifatnya yang mudah membusuk. Berdasarkan bentuknya, sampah organik dibagi menjadi 3 bagian yaitu padat, cair, dan gas.

Sampah jenis padat adalah sampah yang berbentuk padat dan dapat dipegang secara fisik. Sampah padat ada yang mengandung bahan alami (organik) contohnya bangkai hewan, sisa sayuran, kertas dan lain-lain. Sampah jenis cair adalah sampah yang berbentuk cair, artinya dia bisa mengalir ke suatu tempat. Beberapa sampah organik cair yang dihasilkan contohnya urine, juice, dll. Sedangkan sampah jenis gas adalah sisa pembuangan (gas metana) yang dihasilkan manusia dan hewan.

Sampah anorganik adalah sampah yang berasal dari sisa kegiatan manusia, contohnya adalah hasil industri, hasil tambang, dan sampah rumah tangga. Sampah anorganik ini adalah sampah yang sulit untuk diuraikan, biasanya sampah anorganik ini langsung dibuang ke tempat pembuangan akhir atau didaur ulang.

Adapun usaha utama adalah mengurangi sumber sampah dari segi kuantitas dan kualitas. Berbagai cara dapat dilakukan dengan cara: meningkatkan pemeliharan dan kualitas barang sehingga tidak cepat menjadi sampah, meningkatkan efisiensi penggunaan bahan baku, meningkatkan penggunaan bahan yang dapat terurai secara alamiah, misalnya 20 penggunaan pembungkus plastik diganti dengan kertas atau daun, untuk itu diperlukan partisipasi dan kesadaran masyarakat (Soemirat, 2000).

Dalam pengelolaan sampah,Cyprus Sustainable Tourism Initiative Theory's (2017) mengemukakan empat langkah pengelolaan sampah yang baik, yaitu:

1. Re-think/ Berpikir ulang: berpikir sebelum membeli sesuatu, pikirkan apa yang dibeli, dan pikirkan sebelum membuang sampah.

2. Reduce /Mengurangi: upaya yang konsisten dan gigih untuk mengurangi jumlah limbah yang dibuat di hotel.

3. Recycle / Daur ulang: kurangi jumlah sampah yang berakhir di TPA, pastikan bahwa limbah tersebut digunakan sedapat mungkin atau bahan mentah untuk membuat produk baru, melestarikan sumber daya alam, membatasi polusi, menyumbangkan sisa makanan, dan makanan kompos dengan limbah kebun.

4. Reuse / Gunakan kembali: pertahankan dan perbaiki peralatan agar tahan lebih lama dan berfungsi secara efisien.

Program Tanpa Limbah bertujuan untuk memberikan wawasan kepada 3R (Pengurangan, Penggunaan Kembali dan Daur Ulang) yang diakui secara internasional dan pencegahan limbah yang merupakan tindakan prioritas dari hirarki pengelolaan limbah seperti yang dijelaskan dalam Arahan Kerangka Limbah Uni Eropa 2008/98 / EC.Pengelolaan sampah yang dilaksanakan hotel saat ini masih sering terbatas karena pengumpulan limbah dan biaya yang cukup tinggi, ketidakmampuan untuk mengidentifikasi biaya tersembunyi yang terkait dengan pembelian bahan baku, keterlibatan personel dalam pengelolaan limbah, dan banyak hal lainnya yang menjadi penghalang dalam perencanaan sebuah hotel untuk dapat melaksanakan program Tujuan Pembangunan Berkelanjutan khususnya dari sisi lingkungan. Sebagai salah satu contoh, hal ini sama terjadi di Yunani (Tsakona dan Mavropoulos, 2015), dimana industri 


\section{National Conference of Creative Industry: \\ Sustainable Tourism Industry for Economic Development}

Universitas Bunda Mulia, Jakarta, 5-6 September 2018 e-ISSN No: 2622-7436

Hospitaliti yang ada didalamnya masih belum fokus kepada Tujuan Pembangunan Berkelanjutan khususnya dibidang pengelolaan sampah. Hal tersebut masih dianggap remeh dan merepotkan bagi sebagian industri. Dalam penelitiannya Tsakona dan Mavropoulos (2015) merekomendasikan untuk pengelolaan hotel tanpa limbah yang dapat berkontribusi dan bermanfaat besar terhadap hotel. Pengelolaan tanpa limbah di hotel bisa menjadi alat yang berharga bagi pariwisata daerah masing-masing untuk menjadi lebih hijau dan berkontribusi untuk penggunaan bahan-bahan berkelanjutan.

\section{METODE PENELITIAN}

\section{A. Jenis dan Desain Penelitian}

Berdasarkan Fatchan (2011) jenis penelitian ini merupakan penelitian kualitatif yang termasuk dalam tingkat sederhana. Artinya penelitian kualitatif yang berupaya mendeskripsikan satu atau beberapa gejala yang timbul (yang ditampakkan oleh individu, kelompok, atau masyarakat tertentu) seperti apa adanya secara rinci, holistik, dan kontekstual.Berdasarkan variabel yang diteliti maka jenis penelitian dari penelitian ini adalah penelitian deskriptif. Penelitian deskriptif adalah penelitian untuk menemukan fakta dengan interpretasi yang tepat (Nazir, 2003).

Penelitian ini menggunakan pendekatan studi kasus atau penelitian lapangan (field study). Penelitian studi kasus adalah penelitian yang di lakukan guna mempelajari secara intensif tentang interaksi lingkungan, posisi, serta keadaan lapangan suatu unit penelitian secara apa adanya, subjek penelitian dapat berupa individu masyarakat, ataupun institusi. (Fatchan, 2011: 65). Studi kasus dilakukan di kalangan karyawan dan juga beberapa tamu untuk penggunaan dan pengelolaan sampah plastik di Hotel Double Tree by Hilton Jakarta.desain penelitian yang digunakan dalam penelitian studi kasus ini adalah desain kasus tunggal holistik. Dimana studi kasus dalam penelitian ini menguji teori yang dimiliki oleh Cyprus Sustainable Tourism Initiative (2017) yang menyatakan bahwa dalam pengelolaan sampah yang baik dalam hotel dibutuhkan empat tahapan, dimana teori tersebut akan dilihat dari implementasi yang dilaksanakan oleh pihak hotel Double Tree by Hilton Jakarta. Pengembangan instrumen pun dilakukan menggunakan teori tersebut sebagai landasan pertanyaan untuk wawancara bagi para informan yang ada.

\section{B. Teknik Pengumpulan Data}

Penyusunan penelitian ini menggunakan metodologi pengumpulan data sebagai berikut:

1. Pengumpulan Data Primer: Penulis melakukan wawancara kepada Manajemen Double Tree by Hilton Jakarta untuk mendapatkan ijin penelitian serta informasi terkait dengan topik penelitian dan dengan menjadi trainee dan tamu dengan tujuan memperhatikan proses penggunaan plastik dan pembuangan sampah plastik yang ada di dalam hotel

2. Pengumpulan Data Sekunder: Penulis mendapatkan informasi dan masukanmasukan dengan cara membaca buku, jurnal-jurnal dan artikel-artikel yang berkaitan dengan penelitian ini. 
Selain itu Penulis menggunakan informan kunci dan informan biasa sebagai subjek penelitian yang menguasai dan memahami informasi atau fakta dari suatu objek penelitian (Betty, 2010).

\section{Pengecekan Keabsahan Data dan Teknik Analisis Data}

Penulis menggunakan triangulasi data dan juga triangulasi metode dalam pengecekan keabsahan data. Selain itu untuk teknik analisis data kualitatif dilakukan secara interaktif dan berlangsung secara terus menerus sampai tuntas, sehingga datanya sudah jenuh. Teknis analisis data dalam penelitian ini menggunakan model interaktif (Fatchan, 2011). Dimulai dari pengumpulan dan pengelompokan data, reduksi data, penyajian data, dan penarikan kesimpulan.

\section{HASIL PENELITIAN DAN PEMBAHASAN}

Menurut International Hotel and Restaurant Associaton (2016), hotel diklasifikasikan menjadi bintang, lokasi, rencana, lama tamu, tipe tamu, dan jumlah kamar.DoubleTree By HiltonHotel adalah salah satu hotel bintang lima karena hotel memiliki restoran dengan layanan pengiriman 24 jam, pusat kebugaran, parkir valet, dan fasilitas kamar hotel bintang lima. DoubleTree By HiltonHotel terletak di Jalan Pegangsaan Timur No. 17, Cikini, Menteng, Jakarta Pusat, yang menurut lokasi, hotel ini adalah tipe hotel kota. Para tamu yang datang ke hotel sebagian besar adalah pengusaha perjalanan untuk seminar atau pertemuan. Mereka tinggal selama kurang dari satu minggu, oleh karena itu hotel adalah jenis hotel semi residen.

Hotel DoubleTree By Hilton Jakarta juga termasuk dalam jenis hotel di atas ratarata karena menyediakan 250 kamar dengan delapan tipe kamar, yaitu, kamar tamu, kamar deluxe, kamar eksekutif, kamar deluxe eksekutif, satu kamar tidur suite, deluxe satu kamar tidur suite, suite superior, dan presidential suite. DoubleTree By Hilton Jakarta Hotel juga menyediakan tujuh ruang pertemuan dan satu ballroom.Hotel DoubleTree By Hilton Jakarta memiliki enam departemen, yaitu, Front Office Department, Food and Beverage Department, Finance Department, Sales and Marketing Department, Housekeeping Department, and Human Resources Department, dengan masing-masing departemen menghasilkan limbah setiap hari. Limbah yang dihasilkan beragam, misalnya, dari sisa makanan, kertas, hingga botol mineral.

Tabel1. Sumber Limbah Di DoubleTree By Hilton Hotel Jakarta

\begin{tabular}{cccc}
$\begin{array}{c}\text { Jumlah } \\
(\%)\end{array}$ & $\begin{array}{c}\text { Sumber } \\
\text { Limbah }\end{array}$ & $\begin{array}{c}\text { Limbah yang dihasilkan di } \\
\text { DoubleTree By Hilton Jakarta }\end{array}$ & Departemen \\
\hline 10 & Limbah Alam & Daun dan Ranting & $\begin{array}{c}\text { Front Office, } \\
\text { Housekeeping, Food } \\
\text { and Beverage }\end{array}$ \\
\hline 40 & $\begin{array}{l}\text { Limbah Hasil } \\
\text { Manusia }\end{array}$ & Kotoran dan Urin Manusia & \begin{tabular}{c} 
Seluruh Departemen \\
\hline 20
\end{tabular} \\
Limbah & Plastik botol, kertas, majalah, & Seluruh Departemen
\end{tabular}




\section{National Conference of Creative Industry: \\ Sustainable Tourism Industry for Economic Development}

Universitas Bunda Mulia, Jakarta, 5-6 September 2018 e-ISSN No: 2622-7436

Konsumsi makanan dan minuman sisa, paper

Manusia cup, penutup kepala, bungkus

sabun, pasta gigi, dan peralatan

mandi di kamar tamu

Sampah dari persiapan masakan,

kaleng alumunium, plastik

pembungkus makanan atau

30 Limbah minuman, kertas dari setiap

Industri departement, peralatan yang sudah

Seluruh Departemen tidak terpakai; pulpen, baterai, gantungan baju, dan segala peralatan yang digunakan di hotel

Sumber: Olahan Penulis (2018)

Berdasarkan tabel diatas dapat terlihat bahwa limbah industri mendominasi dibandingkan limbah lainnya sebesar 30\%, dimana limbah industri merupakan hasil seluruh sisa kegiatan karyawan di Double Tree by Hilton Jakarta yang dilakukan oleh seluruh departemen yang ada di dalam hotel. Bisa dilihat limbah industri beraneka ragam dan disetiap departement dapat berbeda-beda sesuai dengan produk yang dijual di masing-masing departemen. Setelah limbah industri, kedua terbanyak adalah limbah yang dikonsumsi oleh karyawan maupun tamu yang ada di Double Tree by Hilton Jakarta. Kebanyakan untuk limbah ini tidak hanya makanan atau minuman, tetapi termasuk juga bahan-bahan plastik ataupun kertas yang produknya telah digunakan oleh para tamu maupun karyawan. Adapun untuk sampah alami kebanyakan dihasilkan oleh pihak Front Office, Housekeeping dan Food and Beverage, dikarenakan beberapa dari outlet terletak di luar gedung dan bernuansa alami sehingga banyak berhubungan dengan alam dan banyak juga sampah yang dihasilkan. Begitupun dengan sampah kotoran manusia baik dari tamu dan juga karyawan. Keduanya bernilai $10 \%$ dari jumlah sampah yang dihasilkan oleh hotel tersebut.

Adapun untuk proses pengelolaan sampah setiap harinya di Double Tree by Hilton Jakarta diurus oleh departement Housekeeping yang dikumpulkan oleh Housekeeper masing-masing Departemen dan nantinya untuk dibuang sesuai dengan kategorinya. Berdasarkan hasil observasi yang dilakukan oleh Penulis, tempat sampah yang dimiliki oleh hotel pun beraneka ragam. Di setiap departemen tempat sampah yang digunakan tentunya berbeda, melihat dari sisi kegunaan dan estetika.Menurut Oli (2015), Housekeeping Department mengelola satu tugas utama yaitu mengelola kamar tamu dan kebersihan semua area publik hotel. Belum ada teori yang menyatakan bahwa Housekeeping Departement bertanggung jawab atas pengelolaan sampah di sebuah Hotel, tetapi di Double Tree by Hilton Jakarta, pengeelolaan dari setiap Departemen diurus oleh Housekeeping dimulai dari pengambilan sampah, pemilahan sampah hingga pembuangan terakhir sebelum dijemput oleh truk sampah atau supplier. Hal ini didukung oleh Bapak Jonathan, selaku Housekeeping Officer yang menyatakan bahwa seluruh pengelolaan sampah menjadi tanggung jawab dari Housekeeping Supervisor Public Area.

Double Tree by Hilton Jakarta sendiri akhirnya mengeluarkan program Bye-bye Plastic 2018 pada bulan Februari 2018 kemarin. Hotel DoubleTree By Hilton Jakarta memiliki program bye-bye plastik 2018 dimana hotel mengurangi pemakaian plastik, contohnya take away cup yang digunakan bukan berasal dari plastik tetapi dari singkong 


\section{National Conference of Creative Industry: \\ Sustainable Tourism Industry for Economic Development}

Universitas Bunda Mulia, Jakarta, 5-6 September 2018 e-ISSN No: 2622-7436

yang di recycle. Terbentuknya program ini dikarenakan DoubleTree By Hilton Jakarta memiliki program unggulan yaitu "Travel With Purpose" dimana salah satu tujuannya adalah Hidup Keberlanjutan (Living Sustainability). Hidup keberlanjutan mencakup proyek-proyek yang membantu dalam perlindungan, konservasi dan pemulihan sumber daya alam dan habitat yang diperlukan untuk mempertahankan bisnis kita; proyek yang mendidik dan memberi informasi kepada anggota tim hotel, tamu, dan masyarakat tentang keberlanjutan; dukungan untuk sumber dan pembelian yang berkelanjutan.

Untuk mengukur tingkat efektifitas pengelolaan sampah plastik, khususnya dalam periode dimulainya Program Bye-bye Plastic 2018, Penulis akan mengukur jumlah sampah plastik yang dihasilkan dan juga tingkat efektifitas menggunakan teori dari Cyprus Sustainable Tourism Initiative Theory's (2017) mengenai empat langkah pengelolaan sampah yang baik. Yaitu:

1. Re-think/ Berpikir ulang: berpikir sebelum membeli sesuatu, pikirkan apa yang dibeli, dan pikirkan sebelum membuang sampah.

2. Reduce /Mengurangi: upaya yang konsisten dan gigih untuk mengurangi jumlah limbah yang dibuat di hotel.

3. Recycle / Daur ulang: kurangi jumlah sampah yang berakhir di TPA, pastikan bahwa limbah tersebut digunakan sedapat mungkin atau bahan mentah untuk membuat produk baru, melestarikan sumber daya alam, membatasi polusi, menyumbangkan sisa makanan, dan makanan kompos dengan limbah kebun.

4. Reuse / Gunakan kembali: pertahankan dan perbaiki peralatan agar tahan lebih lama dan berfungsi secara efisien.

Dalam penelitian ini, penulis mengobservasi dan menanyakan kepada pihak terkait yaitu karyawan dan para tamu mengenai kegiatan program Bye-bye Plastic 2018 serta kaitannya dengan teori Pengelolaan Sampah Hotel yang baik.Berdasarkan hasil interview dengan Karyawan di Double Tree by Hilton, sebagian besar karyawan dari berbagai Departemen masih belum mengetahui adanya program ini. Dimana tujuan dari program ini adalah mengurangi sampah plastik. Masih belum adanya sosialisasi secara resmi dari pihak Hotel mengenai program ini. Sehingga para karyawan belum sadar untuk program ini apalagi untuk mencapai tujuan akhirnya. Hal ini berdampak kepada para tamu yang menginap atau menggunakan jasa di dalam Hotel ini. Dengan program yang belum tersosialisasikan, maka para tamu masih belum tergerak dan belum secara sadar untuk dapat membantu Hotel mengurangi sampah yang ada. Khususnya seperti di dalam kamar, dimana sampah plastik dan kertas muncul banyak dari Perlengkapan Tamu. Dari sisi sosialisasi sudah dapat dikatakan Program ini tidak efektif dikarenakan dari karyawan maupun tamu belum mengetahui program ini dan belum menjalankan program ini. Berbeda dengan informasi yang didapat oleh Direktur Human Resources Double Tree by Hilton Jakarta Bapak Raymond Jhonny dimana beliau sudah memulai program tersebut. Belum adanya standar yang khusus untuk program ini membuat program masih belum dapat dijalani dan tujuan yang dicapai pun masih belum dapat tercapai.

Selain itu penulis melakukan pengukuran dalam pengelolaan sampah plastik menggunakan empat tahapan Cyprus Sustainable Tourism Initiative Theory's (2017) yang didukung informasi dari Karyawan dan Tamu Double Tree by Hilton Jakarta. 


\section{National Conference of Creative Industry: \\ Sustainable Tourism Industry for Economic Development}

Universitas Bunda Mulia, Jakarta, 5-6 September 2018

e-ISSN No: 2622-7436

\section{Tahapan Pertama: Re-think / Berpikir ulang}

a. Berpikir Sebelum Membeli Sesuatu

Pihak Double Tree by Hilton dalam operasionalnya menggunakan banyak tipe peralatan dan bahan makanan maupun minuman ataupun alat-alat penunjang lainnya. Kebanyakan dari barang tersebut adalah barang-barang anorganik yang tidak dapat di daur ulang nantinya. Hal tersebut sudah disadari tetapi pihak hotel masih belum dapat mengganti barang-barang penting yang ada di dalam hotel.

b. Pikirkan Apa yang Dibeli

Adapun sampah plastik paling banyak dihasilkan dari kamar tamu dimana setiap kamar mengkonsumsi minimum 2 botol setiap harinya. Dimana tipe botol yang disediakan oleh pihak hotel merupakan botol plastik yang belum dapat di daur ulang. Hal ini dikarenakan masih adanya kerja sama antara hotel dengan pihak ketiga selaku sponsorship untuk ketersediaan botol minum. Sehingga dapat dikatakan pihak Hotel belum berpikir ulang dalam pembelian maupun penggunaan barang-barang yang ada untuk operasional hotel.

\section{c. Pikirkan Sebelum Membuang Sampah}

Dari sisi pembuangan pihak Hotel setidaknya telah sedikit memikirkan untuk memilah sampah walaupun tidak secara detail. Pengolahan sampah plastik dilaksanakan oleh pihak Housekeeping dibantu oleh Security dan Steward Department sebelum diambil oleh Truk Sampah. Dimana sampah plastik, khususnya botol minum saja yang dipisahkan dan dijual kepada pihak ketiga, selain itu semua sampah plastik masih dimasukkan bersama-sama dengan sampah lainnya. Pernyataan tersebut merupakan hasil interview dengan Housekeeping Officer dimana beliau yang menjalani semua proses pengolahan sampahnya. Sehingga belum dapat dikatakan efektif untuk program Bye-bye Plastic di kategori berpikir ulang, karena dari ketiga tahapan yaitu berpikir sebelum membeli, menggunakan dan membuang, pihak Hotel masih belum benar-benar mengurangi jumlah plastik yang ada.

\section{Tahapan Kedua: Reduce / Mengurangi}

a. Upaya yang Konsisten dan Gigih untuk Mengurangi Jumlah Limbah yang Dibuat di Hotel

Berdasarkan observasi lapangan, masih belum ada hasil dari program ini yang terlihat di Hotel selama tiga bulan terakhir. Artinya semua limbah dan sampah yang dihasilkan di Hotel, masih tergantung pada tingkat hunian kamar tamu dan juga tergantung pada kegiatan meeting atau wedding yang dilaksanakan. Pernyataan tersebut disetujui oleh pihak Housekeeping Department, khususnya oleh Bapak Jonathan yang mengumpulkan sampah setiap harinya. Dia selalu melihat tren jumlah sampah tentunya mengikuti seberapa banyak orang yang ada di dalam hotel khususnya untuk tamu. Karena untuk karyawan sendiri sampah plastik yang dihasilkan paling banyak berasal dari bahan baku untuk tamu saja. Belum ada tingkat pengurangan jumlah sampah plastik dari setiap departemen yang terlihat. Padahal berdasarkkan informasi yang didapat sebelumnya, Program Bye-bye Plastic mengusung penggunaan gelas berbahan dasar singkong untuk dapat digunakan di Coffee Shop Double Tree by Hilton Jakarta. Tetapi dari 3 bulan hasil observasi dan menurut Waiter yang ada di Coffee Shop 


\section{National Conference of Creative Industry: \\ Sustainable Tourism Industry for Economic Development}

Universitas Bunda Mulia, Jakarta, 5-6 September 2018 e-ISSN No: 2622-7436

tersebut, gelas yang digunakan masih berbahan dasar plastik dan belum ada himbauan penggantian tipe gelas.

Salah satu tamu atas nama Vania juga menyatakan bahwa dirinya masih belum melakukan program pengurangan sampah plastik di dalam Hotel. Hal ini dikarenakan masih belum ada himbauan juga dan belum ada kesadaran dari diri sendiri akan hal itu. Tetapi Vania memiliki salah satu ide yang mungkin dapat membantu untuk mengurangi sampah plastik yang ada di dalam Hotel. Salah satunya adalah dengan penggunaan thermos atau gelas dengan bentuk unik agar tamu tidak menggunakan botol plastik kemasan dan dapat mengurangi sampah botol plastik.

Dari kedua sudut pandang diatas dapat dinyatakan bahwa tahapan kedua tidak berjalan dan program Bye-bye Plastic tidak efektif dalam hal mengurangi sampah plastik.

\section{Tahapan Ketiga: Recycle / Daur ulang}

a. Mengurangi Jumlah Sampah yang Berakhir di TPA

Jumlah sampah yang ada secara keseluruhan masih mengikuti jumlah tingkat hunian kamar dari Hotel Double Tree by Hilton Jakarta. Terbukti bahwa program Bye-bye Plastic 2018 masih belum dapat mengurangi jumlah sampah plastik yang ada di Hotel. Penulis mengambil sampling sampah air botol mineral yang dimiliki oleh pihak Hotel dimana jumlahnya sesuai dengan tingkat hunian kamar di bulan tersebut.

b. Memastikan Bahwa Limbah Tersebut Digunakan Sedapat Mungkin Atau Bahan Mentah Untuk Membuat Produk Baru

Berdasarkan hasil wawancara dengan Bapak Jonathan, seluruh limbah yang ada diproses langsung ke tempat pembuangan sampah terakhir seperti yang sudah dijabarkan di sub bab sebelumnya. Dimana tidak ada pengolahan limbah khususnya limbah plastik menjadi barang baru atau sebagai produk baru yang digunakan kembali oleh pihak hotel. Hal ini terdukung dengan hasil observasi penulis yang selama 6 bulan juga ikut melihat bagaimana operasional di dalam hotel, khususnya dalam penggunaan plastik.

\section{c. Melestarikan Sumber Daya Alam}

Program Bye-bye Plastic sendiri belum ada program khusus untuk mendaur ulang barang yang telah digunakan oleh para tamu maupun karyawan yang ada di Hotel. Hal ini didukung oleh hasil interview dengan Bapak Raymond dimana beliau menyatakan masih mencari solusi untuk sampah yang dihasilkan dan juga untuk mendaur ulang beberapa jenis sampah plastik yang mudah dan tidak menggunakan biaya terlalu besar. Karena sebagaimana diketahui untuk dpat memproses sebuah plastik, tentunya dibutuhkan alat khusus, staf, waktu dan biaya yang cukup besar untuk pengolahan sampah plastik. Tentunya hal tersebut yang membuat berat pihak hotel dalam memikirkan tahapan daur ulang sampah yang ada di dalam sehingga belum dapat dijalankan. Dari sisi operasional sendiri pihak Hotel masih belum dapat megganti peralatan plastik dengan barang-barang yang lebih mudah terurai oleh alam sehingga dapat dikatakan hotel masih belum menaruh perhatian akan hal ini.

\section{d. Membatasi Polusi}




\section{National Conference of Creative Industry: \\ Sustainable Tourism Industry for Economic Development}

Universitas Bunda Mulia, Jakarta, 5-6 September 2018 e-ISSN No: 2622-7436

Menetapkan program daur ulang adalah langkah selanjutnya menuju penerapan sistem tanpa limbah di hotel. Setelah mengidentifikasi semua sumber dan aliran bahan yang dihasilkan di hotel, Manajer Hotel perlu memutuskan bahan yang akan dimasukkan dalam program daur ulang, tetapi di Hotel Double Tree by Hilton masih belum melaksanakan ini. Usaha yang sudah dilakukan oleh pihak Hotel masih sebatas menjaga polusi dari sampah plastik dengan memisahkan sampah yang ada dari setiap departemen yang ada di dalam hotel untuk dapat diberikan kepada supplier yang telah berlangganan dengan pihak hotel ataupun truk pembuangan sampah.

\section{e. Menyumbangkan Sisa Makanan}

Disamping mendaur ulang sampah, sebenarnya dalam tahapan ini dilaksanakan juga untuk mendonasikan sisa makanan yang dihasilkan. Kembali lagi, pihak hotel masih belum melaksanakan hal ini. Makanan atau minuman sisa tidak didonasikan kepada pihak manapun tetapi langsung disingkirkan dengan tujuan menjaga kualitas makanan. Sehingga tidak ada makanan yang tidak sesuai atau kualitasnya sudah tidak baik disajikan kepada tamu. Selain itu di dalam tahapan ini Hotel bisa menggunakan sampah sebagai kompos tanaman, mengingat sampah plastik yang ada di hotel ini tidak diproses dan dibuang begitu saja tentunya sangat mustahil untuk pihak hotel menggunakan sampah plastik sebagai kompos tanaman yang ada di dalam hotel.

Industri daur ulang lokal yang sudah mapan dan permintaannya terhadap daur ulang (jumlah dan jenis) merupakan parameter utama yang mempengaruhi kelayakan finansial dari program daur ulang. Dalam pengertian ini, sebuah studi teknoekonomi perlu dilakukan sebelum kegiatan daur ulang apa pun. Studi ini perlu mengidentifikasi barang yang dapat didaur ulang untuk dimasukkan dalam program, departemen yang akan berpartisipasi dalam program, jenis dan sarana pengumpulan dan penyimpanan sementara. Selanjutnya, semua biaya yang relevan termasuk pasokan peralatan, dan biaya personil, serta penghematan dari penjualan barang yang dapat didaur ulang akan ditentukan (Tsakona dan Mavropoulos, 2015). Keseluruhan konsep penggunaan ulang masih belum dapat dilaksanakan dan tidak terdukung oleh Program Bye-bye Plastic 2018 karena belum terlaksana.

\section{Tahapan Keempat: Reuse / Gunakan kembali}

a. Pertahankan Dan Perbaiki Peralatan Agar Tahan Lebih Lama Dan Berfungsi Secara Efisien

Pencegahan dan penggunaan kembali limbah berarti menggunakan lebih sedikit bahan baku, penggunaan persediaan dan peralatan yang optimal dan perolehan produk yang lebih tahan, dan mudah diservis. Pencegahan limbah adalah salah satu metode termudah untuk mengurangi limbah karena dapat dikontrol pada saat membeli produk dan jasa. Selain itu, semua sumber daya dan biaya keuangan bahan, manufaktur, tenaga kerja, transportasi, pengemasan, penyimpanan dan pembuangan terbuang ketika produk dibuang (Favro dan Brebbia, 2013).

Penulis melihat bahwa DoubleTree By Hilton Jakarta belum melakukan langkah menggunakan kembali karena mereka masih tidak dapat memelihara dan memperbaiki peralatan. Sebagian besar produk yang mereka gunakan akan dibuang jika sudah rusak. Hasilnya didukung oleh wawancara dengan Ibu Vury dari departemen Food and Beverage di mana Beliau menegaskan bahwa hotel tidak menggunakan kembali produk 


\section{National Conference of Creative Industry: \\ Sustainable Tourism Industry for Economic Development}

Universitas Bunda Mulia, Jakarta, 5-6 September 2018 e-ISSN No: 2622-7436

bekas. Sebagian besar kemasan plastik dibuang dan botol kaca dijual ke pemasok tanpa mempertahankan atau memperbaikinya.

Dari keempat tahapan pengelolaan sampah masih dapat dikatakan program Bye-bye Plastic 2018 belum efektif dalam mengurangi jumlah sampah yang ada di dalam Hotel Double Tree by Hilton Jakarta. Dimana program tersebut sampai saat ini masih belum diketahui oleh Karyawan dan juga Tamu di dalam hotel tersebut.Padahal berdasarkan Cyprus Sustainable Tourism Initiative (2017), pertama kali yang dibutuhkan adala edukasi kepada staff Hotel sendiri untuk dapat mengembangkan program Tujuan Pembangungan Keberlanjutan dalam sebuah perusahaan. Kualitas pun akan meningkat dengan tingginya investasi pelatihan terhadap staff yang dimiliki setiap perusahaan. Hal ini sama seperti program Bye-bye Plastic 2018. Dengan pihak hotel mengedukasi pentingnya dan baiknya tujuan dari program ini tentu para karyawan akan dapat membantu mengurangi tingkat sampah plastik yang ada di dalam Hotel. Dan tentunya efek selanjutnya para staff juga akan membantu para tamu turut serta sadar dan juga menginformasikan tujuan Hotel dengan jelas kepada tamu.

\section{KESIMPULAN DAN IMPLIKASI}

Pengelolaan sampah yang dilaksanakan hotel saat ini masih sering terbatas karena pengumpulan limbah dan biaya yang cukup tinggi, ketidakmampuan untuk mengidentifikasi biaya tersembunyi yang terkait dengan pembelian bahan baku, keterlibatan personel dalam pengelolaan limbah, dan banyak hal lainnya yang menjadi penghalang dalam perencanaan sebuah hotel untuk dapat melaksanakan program Tujuan Pembangunan Berkelanjutan khususnya dari sisi lingkungan. Salah satu program untuk mencapai Tujuan Pembangunan Berkelanjutan di Hotel Double Tree by Hilton dari sisi lingkungan adalah Bye-bye Plastic yang bertujuan mengurangi sampah plastik yang ada di dalam hotel. Berdasarkan empat tahapan pengelolaan sampah dari teori Cyprus Sustainable Tourism Initiative (2017), pengelolaan sampah di Double Tree by Hilton dengan program Bye-bye Plastic 2018 belum efektif dimana, dari keempat tahapan pengelolaan sampah belum semuanya dilakukan dan berhasil sempurna. Baru di dalam tahapan pertama sudah ada aksi tetapi hasil yang diberikan belum maksimal.

Berdasarkan simpulan dari penelitian ini menunjukkan bahwa pengelolaan sampah dengan baik tidak hanya terlihat dari satu sisi aspek saja dengan menggiatkan sebuah program. Hal ini mengandung implikasi agar kedepannya pihak Hotel dapat memulai dari perencanaan akan membuat rancangan program dengan detail terlebih dahulu sehingga dapat menghemat biaya dan meningkatkan kualitas lingkungan di Double Tree by Hilton Jakarta. Adapun rancangan program tersebut dapat berupa deskripsi secara rinci jenis limbah dan sampah yang ada di dalalm hotel, kemudian dapat diklasifikasikan sesuai departemen yang ada di dalam hotel, sehingga dapat terlihat peta produksi sampah terbanyak berasal dari mana dan bagaimana pengelolaannya nanti. Setelah itu hotel bisa memprioritaskan pengurangan jenis sampah dari mana menggunakan peta tersebut. Dan akhirnya Hotel dapat mencatat dan meninjau aktifitas pengelolaan sampah apakah berkurang atau tetap sama seperti sebelumnya. Selain itu pihak Hotel juga harus memberikan tambahan Personil Khusus dalam penanganan hal ini, agar dapat benar-benar fokus dalam mengelola sampah yang ada di dalam Hotel. 


\section{National Conference of Creative Industry: \\ Sustainable Tourism Industry for Economic Development}

Universitas Bunda Mulia, Jakarta, 5-6 September 2018 e-ISSN No: 2622-7436

\section{DAFTAR PUSTAKA}

\section{Buku}

Alfin, Edward. 2015, Pemanfaatan limbah rumah tangga sebagai bentuk implementas dari pendidikan lingkungan hidup, Universitas Indraprasta.

Bardi, James A. 2010, Hotel Front Office Management, The Pennsylvania State University, United State of America.

Budiyantoro, C. 2010, Thermoplastik dalam Industri, Teknika Media, Surakarta.

Fillaeli, Annisa. 2012, Pengolahan Sampah Plastik Menjadi Produk Kerajinan Tangan, Universitas Negeri Yogyakarta, Yogyakarta.

Isawanto, Sudarmadji dan Wahyuni. 2016, Generation of Household Hazardous Solid Waste and Potential Impacts on Environmental Health in Sleman Regency, Yogyakarta.

Nath, Amar. 2014, Profitability and Sustainability From Waste Management Practices in Hotels and Its Impact on Environment. Jaypee Institute of Imformation Technology, A-10, Sector-62, Noida, India.

Nugroho, Panji. 2013, Panduan Membuat Pupuk Kompoas Cair. Pustaka Baru Press, Jakarta.

Oli, Gopal Singh and B. B. Chhetri. 2015, Hotel management. Buddha publications Pvt. Ltd, Kathmandu.

Purwaningrum, Pramiati. 2016, Upaya Mengurangi Timbulan Sampah Plastik di Lingkungan, Universitas Trisakti, Jakarta.

Sofyan, Lusviminda. 2014, Studi Pengelolaan Sampah Hotel Dan Prospek Pengembangannya di Kota Makassar, Universitas Hasanudin, Makassar.

Sugiyono. 2015, Metode Penelitian Kuantitatif, Kualitatif dan R\&D, PT Alfabet, Bandung.

Suyanto, Bagong. 2005, Metode Penelitian Sosial: Berbagai Alternatif Pendekatan. Prenada Media, Jakarta

\section{Jurnal}

Alamendah. 2009, Dampak Plastik Terhadap Lingkungan [Online]. Available: https://alamendah.org/2009/07/23/dampak-plastik-terhadap-lingkungan/ [Diakses 10 February 2018]

Alamendah. 2011, Pengertian dan Proses Daur Ulang [Online]. Available: https://alamendah.org/2011/01/22/pengertian-dan-proses-daur-ulang/ [Diakses 10 February 2018]

Ambari. 2017, Sampah Plastik Semakin Ancam Laut Indonesia, Seperti Apa? [Online]. Available: http://www.mongabay.co.id/2017/09/18/sampah-plastik-semakinancam-laut-indonesia-seperti-apa/ [Diakses 12 March 2018]

Betty. 2013, Pemaknaan Pesan Iklan Bisnis Indonesia Pada Surat Kabar Harian Bisnis Indonesia. Edisi 16 Januari 2012 (Kajian Semiotika). (Undergraduate Thesis, Universitas Esa Unggul, Jakarta, Indonesia). Diambil dari http://digilib.esaunggul.ac.id/UEU-Undergraduate-universitas-esaunggul201132119_BETTY/2873

Botol Plastik Bisa Menjadi Sumber Bencana Lingkungan [Online], 2016. Available: http://pusatkrisis.kemkes.go.id/botol-plastik-bisa-menjadi-sumber-bencanalingkungan [Diakses 21 April 2018] 
El-Newehy, Mohamed. 2016, Plastic Waste Management [Online]. Available: http://fac.ksu.edu.sa/sites/default/files/plastic_waste_management.pdf [Diakses 23 February 2018]

Fishbein, M. 2008, Managing Organic Municipal Waste

Fauzi dan Oktavianus. 2014, The Measurement of Sustainable Development in Indonesia.Jurnal Ekonomi Pembangunan, Volume 15, Nomor 1, hal 68-83

Hafidudin. 2014, Eksistensi Budaya Sebambangan (Kawin Lari) Dalam Masyarakat Adat Suku Lampung Pepadun di Kampung Cugah Kecamatan Baradatu Kabupaten Way Kanan Tahun 2012. (S1 Skripsi, Universitas Lampung, Bandar Lampung, Indonesia). Diambil dari http://digilib.unila.ac.id/1733/9/Bab\%20III.pdf

Karuniastuti, Nurhenu. 2003, Bahaya Plastik Terhadap Kesehatan dan Lingkungan [Online]. Available: http://pusdiklatmigas.esdm.go.id/file/t2-_Bahaya_Plastik_--_Nurhenu_K.pdf [Diakses 13 March 2018]

Mohan, Vikas. 2017, Reduction and Management of Waste in Hotel Industries, Vol 7, Issue 7, hal 34-37.

Omidiaani, Afsanehsadat dan Seyedmohsen Hashemihezaveh. 2016, Waste Management in Hotel Industry in India. International Hournal of Scientific and Research Publications, Vol 6, Issue 9.

Raban, Mulyaji. 2012, Bahaya Plastik Pembungkus Makanan Bagi Kesehatan [Online]. Available: $\quad$ https://mulyaji.wordpress.com/2012/04/19/bahaya-plastikpembungkus-makanan-bagi-kesehatan/ [Diakses 13 March 2018]

Tsakona, Maria dan Mavropoulos, Alexandros. 2015, Zero Waste Hotels: Challenges \&Opportunities, The Greek Case. D-Waste.

Wahyudi, Ekky, Zultiniar, and Edy Saputra. 2016, Processing of Pollypropylene (PP) Plastic Waste Into Oil Fuel by Catalytic Cracking Method Using Synthetic Catalyst. Jurnal Rekayasa Kimia dan Lingkungan, Vol. 11, No.1, hal 17-23. 